\title{
Patterns of productivity changes in hospitals by using Malmquist - DEA Index:
}

\section{A panel data analysis (2011-2016)}

\section{Behzad Raei ${ }^{1}$, Mahmood Yousefi $^{2}$, Kolan Rahmani ${ }^{3}$, Somaie Afshari ${ }^{1}$, and Hosein Ameri ${ }^{4}$}

1. School of Public Health, Tehran University of Medical Sciences, Tehran, Iran

2. Iranian Center of Excellence in Health Management, School of Management and Medical Informatics,

Tabriz University of Medical Sciences, Tabriz, Iran

3. International Campus, Shahid Sadoughi University of Medical Science, Yazd, Iran

4. Department of Health Management, School of Public Health, Yazd Shahid Sadoughi University of Medical

Sciences, Yazd, Iran

\section{RESEARCH}

Please cite this paper as: Raei B, Yousefi M, Rahmani K, Afshari S, Ameri H. Patterns of productivity changes in hospitals by using Malmquist - DEA Index: A panel data analysis (2011-2016). AMJ 2017;10(10):856-864. https://doi.org/10.21767/AMJ.2017.3094

\section{Corresponding Author:}

Hosein Amery

Department of Health Management, School of Public Health, Yazd Shahid Sadoughi University of Medical Sciences, Yazd, Iran

Email: Hamery7@yahoo.com

\section{ABSTRACT}

\section{Background}

In Iran, governmental hospitals operate under a fixed budget and without a price- driven market, they need to produce health care more efficiently to guarantee providing more services.

\section{Aims}

The main objective of the present study is to investigate the productivity of the Yazd hospitals before and after the implementation of the health system transformation plan (HSTP).

\section{Methods}

This study is a descriptive-analytical kind conducted by applying a panel data for a six-year time horizon. The study was carried out on 11 teaching and non-teaching hospitals of Yazd Province. DEA technique with an input- oriented approach and Malmquist indices were used to estimate the efficiency and productivity. Data were analysed using Excel.22 and DEAP.2 software.

Results

Our results showed that, except for 2014-2015, there was a positive change in efficiency for a quite large proportion (66 per cent) of the hospitals within the study period. The technological changes demonstrated generally negative trend for most parts of the time period in the study 20112012 aside. Geometric mean of Malmquist index showed a positive alteration in 2011-2012 and 2015-2016 and negative shift for the remaining time periods.

\section{Conclusion}

Estimates on the basis of Malmquist index displayed that five-year average Malmquist index and technology change were 92 per cent and 91 per cent, respectively showing a regress in the concerning measures.

\section{Key Words}

Malmquist index, efficiency, productivity

\section{What this study adds:}

\section{What is known about this subject?}

There is a changing trend in the productivity of hospitals affiliated to Yazd with establishing HSTP in Iranian health system.

\section{What new information is offered in this study?}

There was no relationship between productivity changes and its elements with HSTP in study time horizon.

3. What are the implications for research, policy, or practice?

If governmental hospitals are to extend their scale and domains of services providing, they have no option but to 
operate efficiently and this goal can be to a large extent achieved through improving human resource productivity or downsizing the government employees of the hospitals.

\section{Background}

Hospitals because of the essential role in providing health care may be entitled as a first place of focus for economic problems within the health sector. Whereas, in developing countries 30-50 per cent of health care expenditures are spent on hospital services, ${ }^{1}$ factors like variation in per capita service utilization, population growth and increase in price have led to a growth in hospital expenditures. ${ }^{2}$ In a report by Health Affairs it was estimated that the growth in total hospital expenditure would be 2 per cent higher than that in GDP in 2006-2015. ${ }^{3}$ reports on, health expenditure in Iran demonstrated a 2.5 fold increase in per capita expenditure from 2002-2014. ${ }^{4}$ Increasing in health expenditure and limited public budget during the past decades have obliged decision makers to find ways to improve health status. ${ }^{5}$ In the current economic space in Iran, it is hard to increase the level of health care resources utilized. On the other hand, spending more on health is not always desirable because additional health gain from utilizing more resources, especially at high level of expenditure, may be very little. ${ }^{6}$ Thus, the only way for the purpose of health improvement is the efficient use of existing resources in Iran's health sector. This issue can be a major concern for healthcare managers endeavoring to enhance quality and contain costs. ${ }^{7}$ General hospitals efficiency, meanwhile, has received the attention of many scholars and academics because of being absorbed heavy health expenditures by this industry. ${ }^{8-10}$

According to an initial definition by Farrell, technical efficiency refers to producing a given number of outputs by using the minimum number of inputs; alternatively, producing the maximum amount of output by a given input. $^{11}$ A firm operating on frontier is considered technically efficient. In the literature of performance, efficiency and productivity, these two terms have been used interchangeably, but productivity indicates a broader concept which efficiency measurement is a part of that. Productivity is the ratio of an index of output to an index of input employment. Productivity change stems from efficiency change and/or technological changes. ${ }^{12}$

Health system of Iran is an integrated system in a way that health care delivery and medical education are under supervision of the Universities affiliated Medical Sciences (UMS). These entities are executive bodies to the Ministry of Health policies and plans and totally 58 UMS located in
31 Provinces in the entire country. In recent years the Ministry of Health and Medical Education (MHME) has implemented several innovative plans including family physician system and health system transformation plan (HSTP) to overcome underperformances in the area of health care delivery. The latest plan was the "health system transformation plan (HSTP)". This is a nation-wide plan which implemented in the governmental hospitals which are affiliated to the UMS. The main objective of the present study is to investigate the productivity of the hospitals affiliated to Yazd University of Medical Sciences before and after the implementation of the HSTP reform since 20112016. Indeed, the main research question examined in this study is ' what is the impact of HSTP on hospital efficiency?

Recent reforms in Iranian health care system, that is, HSTP is a nationwide plan implemented by MHME at the hospitals affiliated universities of medical science in line with achieving universal health coverage since May 5, 2014. This plan includes several executive packages, two of which directly pertained to the hospitals affiliated to MHME. These relevant packages are as follows:

- Diminishing out-of-packet payments by 10 per cent of total hospitalization expenditure for inpatients in the hospitals affiliated to MHME

- Improving the quality of care for the hospitals affiliated with MHME

- There are several financing sources associated with HSTP. These sources include: increased share of health sector budget (e.g., up to 59 per cent in year 2015 relative to 2014), resources obtaining through the earmarked (targeted) subsidies, and a specific 1 per cent added value tax belonging in health sector. ${ }^{13}$

\section{Method}

The main goal of For-profit hospitals is to maximize profit for stockholder. Therefore, they make an attempt to produce services efficiently. Non-profit hospitals mainly focus on satisfying health care need, expanding into training and re-education of their staff irrespective of profit. ${ }^{13}$ In Iran, governmental hospitals are mainly subsidized by government and may upsize their scale. Because of the importance of higher technical efficiency in governmental hospitals, the sample is composed of 11 governmental hospitals affiliated the Yazd University of Medical Science. Four (36 per cent) of 11 Hospitals are located at the capital of Yazd. These hospitals are Shahid Sadugi, Shohadaye Mehrab, Afshar and Rahnomon Hospital. Shahid Sadugi hospital included all Wards such as General and specialized ones. Shohadaye Mehrab hospital mainly provides services for burn patients whereas Afshar and Rahnomon Hospitals 
largely do for cardiac disease and trauma respectively. Amid hospitals situated in the county area, Ardakn and Meybod hospitals possess the largest number of wards and units in comparison with other hospitals having Surgery, orthopaedics, intensive care unit (ICU) and Obstetrics units.

Given that private hospitals do run for profit, they put cost containment strategies including operating on efficiency frontier and/ or revenue maximization like marketing and pricing ones on the agenda. In contrast, government hospitals do not involve in for-profit activities; and often operate under fixed budget. If governmental hospitals are to extend their scale and domains of services that provide, they have no option but to operate efficiently. Henceforth, it seems that efficiency in governmental hospitals is more important than that in private ones.

\section{Data and variable}

The data for this study was extracted from the report issued by the Deputy of Treatment Affairs affiliated to Shahid Sadoughi University of Medical Science. The data of 11 hospitals for a six-year period of time were studied.

\section{Input and output}

Based on data available, we selected 3 input and 2 outputs. The inputs included total number of physician and nonphysician staff and hospital beds. The outputs included total number of admissions and number of Mortalities per hospital. The description of input and output variables are shown in Table 1. Rationale behind for choosing aforementioned types of inputs and outputs returns to the studies by Ozcan et al. they stated the number of beds acts as a proxy for capital investment and medical staff for labor in hospital service production. In output side, the number of visits and admissions are common. ${ }^{12}$

\section{Methodology}

This is a descriptive-analytical study conducted in 2017 by employing panel data in a six-year time horizon. Malmquist index is used to evaluate the productivity changes of a DMU from one period to another. This index is equated with the product of "Catch-up" and "Frontier-shift" terms. Catch-up is related to efficiency changes, while frontier-shift is associated with technological alteration. To graphically illustrate a DEA Malmquist model, suppose a DMU with a single input and output as evident in the Figure 1.

DMUO in the period of 1 and 2 is located in points $p$ (xo1, yo1) and $Q$ (xo2, yo2), respectively. Catch-up is defined as following equation:
Catch $-\mathrm{UP}=\frac{\frac{B D}{B Q}}{\frac{A C}{A P}}=\frac{\text { Efficiency of point } Q \text { relative to the frontier of period2 }}{\text { Efficiency of point } \mathrm{P} \text { relative to the frontier of period } 1} \quad$ Equeation(1)

The Frontier - shift is calculated based on the following formula.

$\varphi 1=\frac{A C / A P}{A E / A P}=\frac{\text { Efficiency of point } P \text { relative to the frontier of period } 1}{\text { Efficiency of point } P \text { relative to the frontier of period } 2} \quad$ Equeation(2)
$\varphi 2=\frac{B F / B Q}{B D / B Q}=\frac{\text { Efficiency of point } Q \text { relative to the frontier of period } 1}{\text { Efficiency of point } Q \text { relative to the frontier of period } 2} \quad$ Equeation(3)

Then, frontier-shift effect is measured by the following equation as geometric mean of $\phi 1$ and $\phi 2:$

$$
\text { Frontier - shift }=\sqrt{\varphi 1 \times \varphi 2} \text { Equation (4) }
$$

Based on the equation 1 and 4, Malmquist index is equal to Catch-up multiplied by Frontier shift as the equation below: ${ }^{15}$

Malmquist index $=$ Catch up $\times$ Frontier - shift ${ }_{\text {Equation (5) }}$

This study aimed to calculate the Malmquist productivity index for each of the 11 hospitals in the sample using the software DEAP. Also, two components of the Malmquist index: efficiency change (Catch-Up) and technology change (frontier shifts) were calculated (equation 1 and 4). These indices were measured for all consecutive periods from 2011-2016. This time frame, included three years before and three years after the HSTP.

\section{Results}

Descriptive statistics of the variables for 2011 and 2016 are shown in Table 3. Table 3 shows that inpatient admission for Yazd hospitals increased by 79 per cent from 2011-2016, in contrast inverse proportion of inpatient mortality decreased by 28 per cent during the study period. In other words, the rate of inpatient mortality has increased by 28 per cent in inputs side of the model.

The number of non-physician personnel has increased by 132 persons (43 per cent). At the same time, the number of hospital beds has grown by 15 beds (12 per cent). On the one hand, the slight increase in the number of beds has a high running cost in organizational infrastructure and on the other hand, the increase in visits represents a fundamental shift from ambulatory services to inpatient care. The number of physician staffs has nearly remained constant.

Data envelopment analysis revealed that the average efficiency score of Yazd hospitals has remained nearly 
constant during the study time frame. Those hospitals having gained score equalling one denote the optimal application of inputs to produce outputs. These decision making units serve as benchmarks for inefficient peers. In this study, four out of 11 hospitals, namely Mehrab, Abarkuh, Herat and Bafgh were in the efficient category for the all of time period 2011-2016. On the whole, the average efficiency score for hospitals was 60 per cent, showing 40 per cent inefficiency for them. It can be said that, on average, the hospitals can tend to use inputs less efficiently. Inefficient hospitals in comparison to efficient ones use 37 per cent more inputs. In other words, inefficient hospitals can reduce their inputs by 37 per cent in order to reach efficiency frontier.

The findings illustrate that there were fluctuations in efficiency change among hospitals and also across the years represented in Figure 2. Our results showed that more than half of the hospitals had positive changes in efficiency for all time period except for 2014-2015. No hospital was found to be positive changes in efficiency in all period from 20112016. Between 2015 and 2016, all of hospitals except two ones experienced positive changes. For all hospitals the results revealed positive, negative or no changes in efficiency.

Technology changes from 2011-2016 have been shown in Figure 3. The analysis illustrates technological changes of 1.05 (geometric mean) during 2011-2012, which decreased to 91 per cent in 2015-2016 (see also Figure 4). For all of the time period in the study except for 2011-2012, on average, the hospitals experienced negative change in technology. Although Between 2011 and 2012, 8 hospitals represented positive shift in technology but in next two consecutive years more than eight hospitals underwent negative alteration in technology. In terms of geometric mean of technology change, the direction of growth is negative in all periods except for period as 2011-2012 with five per cent positive growth. We observed no hospital had a positive technology change from 2013-2016.

Finally, non-stable trend in the duration of the analysis period was found. Geometric mean of Malmquist index showed a positive alteration in 2011-2012 and 2015-2016 and negative shift for the remaining time periods. Depending on our findings, there were time periods with regressive trend and periods with progress in Malmquist index for each hospital. Figure 4 displays changes in the productivity index. From Figure 5 we find out that no hospital experienced a clear-cut negative or positive changes in Malmquist- based productivity index. A large number (7 out of 12) of hospitals through the study time frame had a negative change in terms of productivity. The maximum change in Malmquist index attributed to time between 2011 and 2012 with nine per cent change.

\section{Discussion}

The trends of efficiency change, technological change, and Malmquist productivity index were obtained for the analysis period between 2011 and 2016. The findings fluctuate throughout the time, That is, there has been an overall nonstable performance among hospitals over the study time period. Technological changes, for instance, revealed a negative growth (4-19 per cent) in four out of five periods (2012-2016) and a positive growth (five per cent) only in 2011-2012.

Generally, based on paired T-test, we obtained evidence that the implementation of health system transformation plan (HSTP) has no statistically significant effect on Malmquist productivity index ( $\mathrm{MI}$ mean before: 0.91 , mean after: 0.93 (95 per cent $\mathrm{Cl}$ : -0.1-0.06; $\mathrm{P}=0.6$ ).

It seems that productivity change is attributed to technology shift in all periods except for 2015-2016 When productivity shift has been influenced by efficiency changes than technological ones. Between 2014 and 2015 positive efficiency changes were found for many hospitals. As already invoked, at the early of year 2014 the HSTP began to be implemented in the governmental hospitals. Because of a reduction in out of packet payment resulting from the HSTP implementation only in governmental hospitals by 10 per cent in inpatient cares, the number of admissions in governmental hospitals had increased dramatically in 2014. It seems that this is the reason why the number of admissions had increased and positive efficiency changes were observed for seven out of 11 hospitals in that time period.

The rather negative productivity tendencies obtained in this study may be due to being unable to cover any changes in quality of outputs or inputs. It should be noted that no input was reflected as a proxy for equipment or building services in the present study. Depending on the results obtained for Malmquist Index, on the average, there is approximately one per cent progress between 2011 and 2012, and four per cent in 2015-2016. From 2012-2015, on average, there were 12 per cent, 13 per cent, and 14 per cent, falls in productivity respectively. It seems that the establishment of HSTP only has produced small positive effect on technology changes from 2014-2016. Put the other way round, after establishing HSTP, the mean of efficiency change has 
decreased by six per cent in 2014-2015 but increased by eight per cent in 2015-2016. all things considered, seven of 11 hospitals experienced average annual technical efficiency.

Torabipour et al. in a study conducted in 12 teaching and non-teaching hospitals of Ahvaz County observed that the trend of productivity rate had been increasing generally. But, the hospitals had a decreasing total average of productivity. ${ }^{16}$ It seems that the results of their study are in line with our findings. Malmquist index approach in comparison to other productivity-related index like Tornqvist, Laspeyres, or Paasche has several advantages. This index is capable to measure technical and technological change. It also is free of requiring data on price and allows for administrating multiple outputs and inputs without integration. $^{17}$

A study by Bwana on not-for- profit hospitals in Tanzania revealed that Volunteering Agency Hospitals (VAH) in Tanzania experienced 1.6 per cent regress in effeciency per year during the period under the study. ${ }^{18}$

Valdmanis and colleagues carried out a study to examine the performance change by Malmquist approach in Scottish hospitals over 2003-2007. They did not find a constant tendency in Malmquist index, the efficiency index, and the technology change over the aforementioned time horizon. There appears the result of this study to be more concordant with our study results. ${ }^{19}$

\section{Conclusion}

We calculated Malmquist index and DEA efficiency scores for a panel data set covering 11 Yazd governmental hospitals throughout the period between 2011 and 2016. Since, in Iran, governmental hospitals operate under a fixed budget and without a price- driven market, they need to produce health care more efficiently to guarantee providing more services. Estimates on the basis of Malmquist index displayed that five-year average Malmquist index and technology change were 92 per cent and 91 per cent, respectively that Show a regress in those indices. The rather downward productivity trend in the present study might be reasonably claimed that there has not been a proxy indicating disparities in quality of outputs and/or inputs. The omission of quality measures can have-and probably should have- an important implication for the findings.

Five-year average efficiency change was greater than one implying a slight increase in efficiency. Seven out of 11 hospitals experienced 5-Year average technical progress, and only four out of 11 exhibited negative growth in efficiency. In spite of being significant fluctuations among Yazd hospitals regarding efficiency change scores from one year to the other, one hospital (Harat) has been operating on efficiency frontier in all years of the analysis. Depending on our model in the current study, from 2011-2016; efficiency change has increased by 13 per cent while technology changes decreased by nine per cent and in doing so, Malmquist index has increased by three per cent. Evidently, the implementation of the HSTP as a new health financing system in governmental hospital has not yet led to the noteworthy improvement in technical efficiency which is to be one of the main purposes of the governmental financing system. Future research is to worth considering different time periods and variables especially quality ones in order to allow comparisons across alternative methodologies and to identify policy reforms that correlate with a certain dynamic trend of productivity.

\section{Limitation}

First, the quality aspects of inputs and outputs have not been considered due to the lack of quality assessment across the Yazd hospitals, that is, there is no data following DRGs and medical classification of patients in Iranian health system. Secondly, our sample was limited to the hospitals belonging to one province (Yazd) so that it is difficult to generalize our findings to other settings. Finally, our study has suffered from some methodological shortcomings, since DEA-based technics are sensitive to the number of inputs and outputs in relation to the number of DMUs. Future research is suggested to focus on including exogenous variables such as geographical access to a hospital, type of health insurance coverage and so forth.

\section{References}

1. Mills A. The economics of hospitals in developing countries. Part I: expenditure patterns. Health policy and planning. Health Policy Plan. 1990;5(2):107-17. https://doi.org/10.1093/heapol/5.2.107.

2. Berndt ER, Cutler DM, Frank R, et al. Price Indexes for Medical Care Goods and Services--An Overview of Measurement Issues. Medical care output and productivity: University of Chicago Press; 2001;141-200. doi:10.3386/w6817

3. Borger C, Smith S, Truffer C, et al. Health spending projections through 2015: changes on the horizon. Health Aff (Millwood). 2006;25(2):w61-73. Epub 2006 Feb 22. doi: 10.1377/hlthaff.25.w61. [PubMed: :16495287]

4. Farrell C. Patient and public involvement in health: the evidence for policy implementation: a summary of the 
results of the Health in Partnership research programme: Department of Health; 2004.

5. Tiemann O, Schreyögg J. Changes in hospital efficiency after privatization. Health Care Manag Sci. 2012;15(4):310-26. doi: 10.1007/s10729-012-9193-z. [PubMed: 22297925]

6. Organization WH. The world health report 2000: health systems: improving performance: World Health Organization; 2000.

7. Bahadori M, Tofighi S, Ameriun A, et al. Evaluation of input indicators related to human resource productivity in a military hospital in Iran. Health Med. 2010;4(2):3237.

8. O'Neill L, Rauner M, Heidenberger $\mathrm{K}$, et al. A crossnational comparison and taxonomy of DEA-based hospital efficiency studies. Socioecon Plann Sci. 2008;42(3):158-89. https://doi.org/10.1016/j.seps.2007.03.001

9. Ozcan YA, Luke RD, Haksever C. Ownership and organizational performance: a comparison of technical efficiency across hospital types. Med Care. 1992;30(9):781-94. [PubMed: 1518311]

10. Hofmarcher MM, Paterson I, Riedel M. Measuring hospital efficiency in Austria-a DEA approach. Health Care Manag Sci. 2002;5(1):7-14. [PubMed: 11860081]

11. Hollingsworth B. Non-parametric and parametric applications measuring efficiency in health care. Health care management science. Health Care Manag Sci. 2003;6(4):203-18. [PubMed: 14686627]

12. Ozcan YA. Health care benchmarking and performance evaluation. An assessment using data envelopment analysis (DEA). 2008.

13. Piroozi B, Moradi G, Nouri B, et al. Catastrophic health expenditure after the implementation of health sector evolution plan: a case study in the west of Iran. Int J Health Policy Manag. 2016;5(7):417-423. doi: 10.15171/ijhpm.2016.31. [PubMed: 27694669]

14. Lee $\mathrm{KH}$, Yang SB, Choi M. The association between hospital ownership and technical efficiency in a managed care environment. J Med Syst. 2009;33(4):307-15. [PubMed: 19697697]

15. Cooper WW, Seiford LM, Tone K. Introduction to data envelopment analysis and its uses: with DEA-solver software and references: Springer Science \& Business Media; 2006. doi: 10.1007/0-387-29122-9

16. Torabipour A, Najarzadeh M, Mohammad A, et al. Hospitals productivity measurement using data envelopment analysis technique. Iran J Public Health. 2014 Nov;43(11):1576-81.[PubMed: 26060727]

17. Färe R, Grosskopf S, Lindgren B, et al. Productivity developments in Swedish hospitals: a Malmquist output index approach. Data envelopment analysis: theory, methodology, and applications: Springer; 1994;253-72. doi: https://doi.org/10.1007/978-94-011-0637-5_13

18. Bwana K. Evaluating the Productivity of Faith based Hospitals in Tanzania: Application of Malmquist Productivity Index (MPI) Approach. Int J Financ Econ. 2014;3:207-16.

19. Valdmanis V, Rosko $M$, Mancuso $P$, et al. Measuring performance change in Scottish hospitals: a Malmquist and times-series approach. Health Serv Outcomes Res Methodol. 2017;17(2):113-26. doi: 10.1007/s10742016-0151-y

\section{ACKNOWLEDGEMENTS}

We would like to express our gratitude to the deputy of medical of the Shahid Sadoughi University of Medical Science, for providing us access to the relevant data for this study. The perceptions expressed in this article are attributable to authors solely and do not reflect decision or associated policies of the organizations are affiliated with Shahid Sadoughi University.

\section{PEER REVIEW}

Not commissioned

\section{CONFLICTS OF INTEREST}

The authors declare that they have no competing interests.

\section{FUNDING}

There were no financial resources

\section{ETHICS COMMITTEE APPROVAL}

The authors present their adherence to ethical issues (covering Confidentiality, plagiarism, misconduct, data fabrication and/or falsification, double submission and/or, publication redundancy, etc.). 
Table 1: Decision making units

\begin{tabular}{|c|c|c|c|c|c|c|c|c|c|c|c|}
\hline & H1 & $\mathrm{H} 2$ & H3 & H4 & H5 & H6 & H7 & H8 & H9 & H10 & H11 \\
\hline Hospital & $\begin{array}{l}\frac{1}{\pi} \\
\frac{5}{4} \\
\frac{4}{<}\end{array}$ & 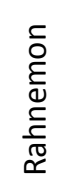 & $\begin{array}{l}\frac{0}{\pi} \\
\frac{\pi}{\frac{\pi}{\pi}} \\
\frac{\pi}{2}\end{array}$ & 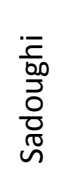 & 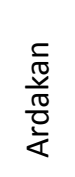 & $\begin{array}{l}\overline{0} \\
\overline{0} \\
\dot{\lambda}\end{array}$ & $\underset{I}{\stackrel{t}{T}}$ & $\begin{array}{l}\frac{c}{\vec{J}} \\
\frac{\vec{v}}{\sqrt{\pi}} \\
\frac{0}{<}\end{array}$ & 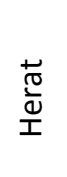 & $\begin{array}{l}\stackrel{N}{\Sigma} \\
\frac{\pi}{\mathbb{U}} \\
\sum\end{array}$ & $\begin{array}{l}\frac{c}{600} \\
\stackrel{40}{\pi} \\
\infty\end{array}$ \\
\hline
\end{tabular}

Table 2: Inputs and outputs selected for a DEA- Malmquist model

\begin{tabular}{|c|c|}
\hline Variables & Definition and measurement \\
\hline $\begin{array}{c}\text { Inputs } \\
\text { physicians } \\
\text { Beds } \\
\begin{array}{c}\text { Non- physician } \\
\text { employee }\end{array}\end{array}$ & $\begin{array}{r}\text { The number of Specialist and general physicians is a major indicator of labour } \\
\text { The number of beds is an accepted proxy for hospital capitals }\end{array}$ \\
$\begin{array}{c}\text { Outputs } \\
\text { Thertality in patients }\end{array}$ & Number of other personnel including nurse, laboratory technician and ... \\
Admission & The number of admissions is a widely accepted metric of a hospital workload \\
\hline
\end{tabular}

Table 3: Descriptive statistics from 2011 to 2016 study periods

\begin{tabular}{|c|c|c|c|c|c|c|c|}
\hline Variables & $\begin{array}{l}2011 \\
\text { Mean(SD) }\end{array}$ & $\begin{array}{l}2012 \\
\text { Mean(SD) }\end{array}$ & $\begin{array}{l}2013 \\
\text { Mean(SD) }\end{array}$ & $\begin{array}{l}2014 \\
\text { Mean(SD) }\end{array}$ & $\begin{array}{l}2015 \\
\text { Mean(SD) }\end{array}$ & $\begin{array}{l}2016 \\
\text { Mean(SD) }\end{array}$ & $\begin{array}{l}\text { 2011-2016 } \\
\% \text { change }\end{array}$ \\
\hline $\begin{array}{l}\text { Inputs } \\
\text { non- } \\
\text { physician } \\
\text { Bed } \\
\text { physician }\end{array}$ & $\begin{array}{l}302(216) \\
121 \\
-89 \\
46 \\
-42\end{array}$ & $\begin{array}{l}319 \\
-215 \\
125 \\
-95 \\
35 \\
-32\end{array}$ & $\begin{array}{l}301 \\
-212 \\
125 \\
-97 \\
38 \\
-36\end{array}$ & $\begin{array}{l}362 \\
-243 \\
125 \\
-100 \\
38 \\
-37\end{array}$ & $\begin{array}{l}433 \\
-352 \\
126 \\
-105 \\
43 \\
-38\end{array}$ & $\begin{array}{l}434 \\
-339 \\
136 \\
-110 \\
46 \\
-41\end{array}$ & $\begin{array}{l}43 \% \\
12 \% \\
0\end{array}$ \\
\hline $\begin{array}{l}\text { Outputs } \\
\text { inpatient } \\
\text { admission } \\
\text { inverse } \\
\text { proportion } \\
\text { of inpatient } \\
\text { mortality }\end{array}$ & $\begin{array}{l}124808 \\
(62632) \\
0.025 \\
\\
(0.036)\end{array}$ & $\begin{array}{l}128489 \\
(57589) \\
0.026 \\
\\
(0.035)\end{array}$ & $\begin{array}{l}143318 \\
(62228) \\
0.023 \\
(0.031)\end{array}$ & $\begin{array}{l}180669 \\
(78747) \\
0.023 \\
\\
(0.027)\end{array}$ & $\begin{array}{l}216517 \\
(104502) \\
0.018 \\
(0.019)\end{array}$ & $\begin{array}{l}223557 \\
(124548) \\
0.018 \\
(0.017)\end{array}$ & $\begin{array}{l}+79 \% \\
-28 \%\end{array}$ \\
\hline
\end{tabular}

Table 4: Number of efficient and inefficient hospitals and their scores

\begin{tabular}{|c|c|c|c|c|c|c|}
\hline \multirow{2}{*}{$\begin{array}{l}\text { Study } \\
\text { period }\end{array}$} & \multirow{2}{*}{ Sample } & \multicolumn{2}{|c|}{ Efficient } & \multicolumn{2}{|c|}{ Inefficient } & \multirow{2}{*}{$\begin{array}{l}\text { Mean } \\
\text { efficiency } \\
\text { score }\end{array}$} \\
\hline & & $\%$ & NO & $\%$ & NO & \\
\hline 2011 & 11 & 36 & 4 & 64 & 7 & 0.598 \\
\hline 2012 & 11 & 36 & 4 & 64 & 7 & 0.6 \\
\hline 2013 & 11 & 36 & 4 & 64 & 7 & 0.604 \\
\hline 2014 & 11 & 36 & 4 & 64 & 7 & 0.597 \\
\hline 2015 & 11 & 27 & 3 & 73 & 8 & 0.602 \\
\hline 2016 & 11 & 36 & 4 & 64 & 7 & 0.601 \\
\hline Overall & 66 & 34 & 23 & 66 & 43 & 0.6 \\
\hline
\end{tabular}




\section{Figure 1: Catch-up}

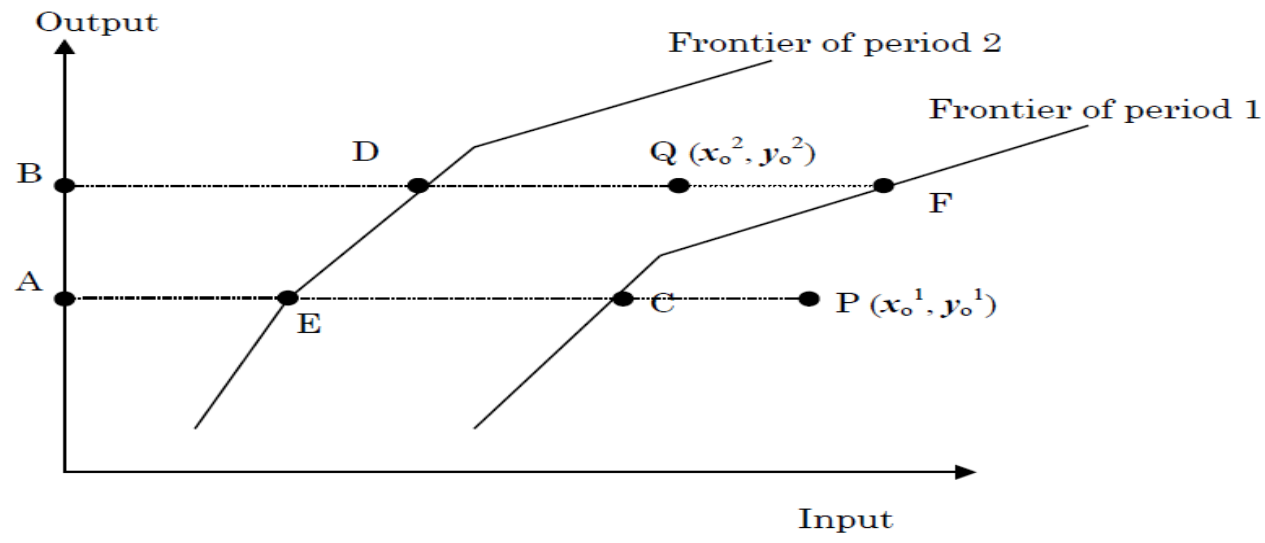

Figure 2: The trend of efficiency changes among DMUs

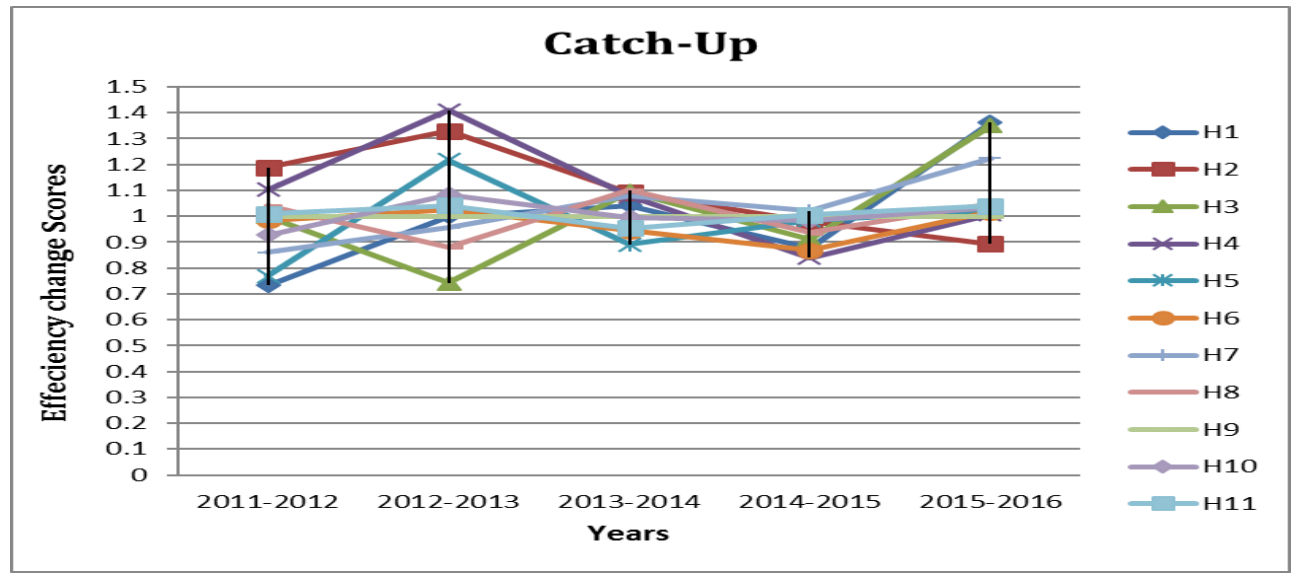

Figure 3: Technology change in DMUs

Frontier-Shift

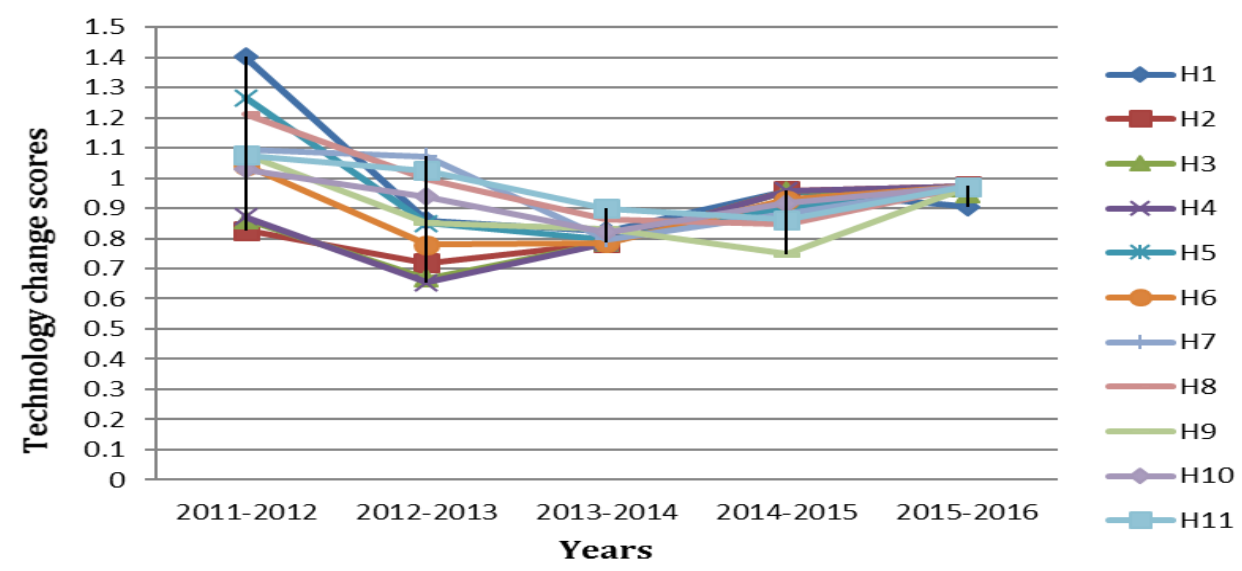


Figure 4: Productivity changes among DMUs

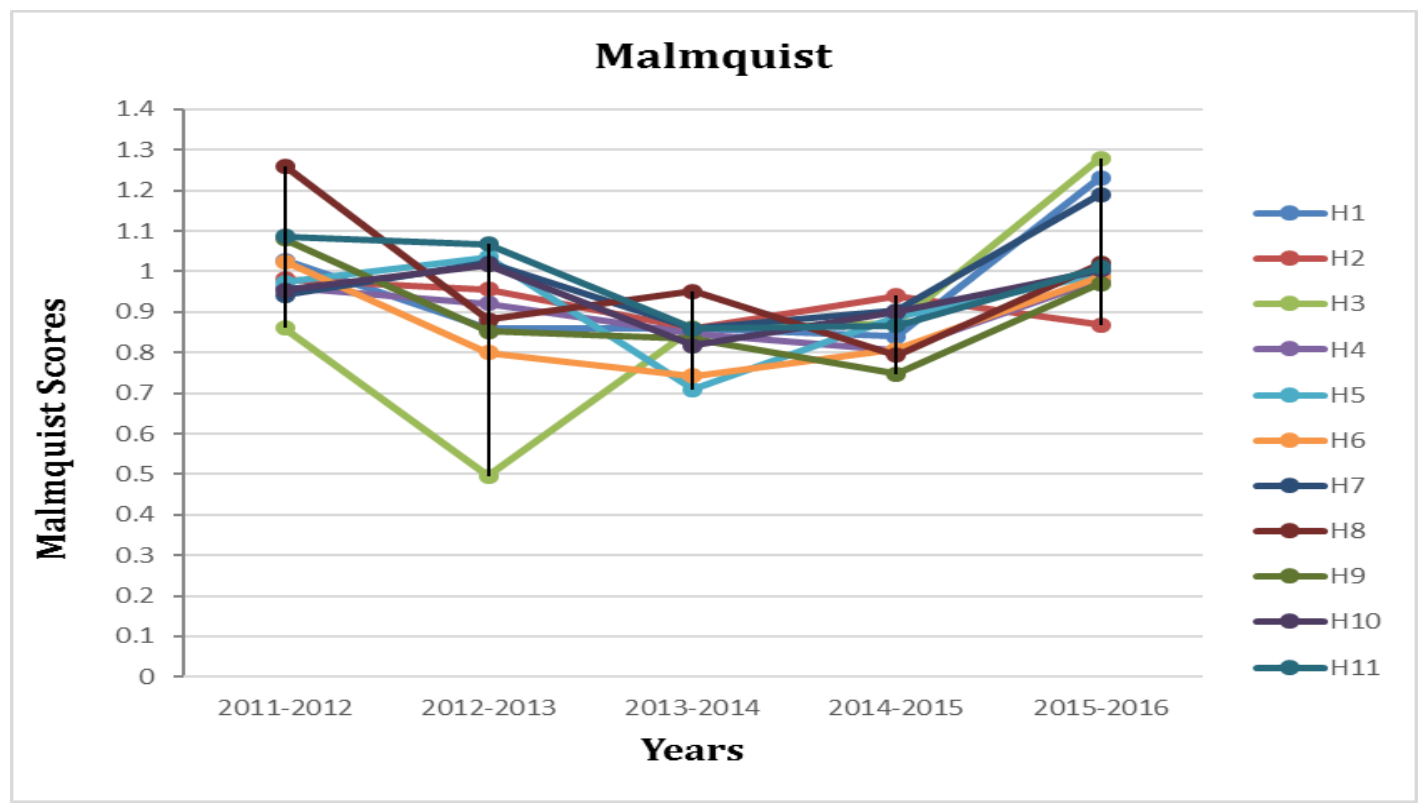

